\title{
Ordered Structure Analysis of Prepared Mesoporous Silica Using Small Angle X-Ray Scattering
}

\author{
A.I.W.S. Ramadani ${ }^{1}$, N.S. Pamungkas ${ }^{1}$, N.A. Putrisetya ${ }^{1}$, M.C. Prihatiningsih ${ }^{1}$, \\ M.D. Permatasari ${ }^{2}$, A.A. Nugroho' ${ }^{2}$, S. Suyanta ${ }^{2}$, A. Patriati ${ }^{3}$, S. Soontaranon ${ }^{4}$ \\ and E.G.R. Putra ${ }^{1,3}$ \\ ${ }^{I}$ Polytechnic Institute of Nuclear Technology, National Nuclear Energy Agency, Yogyakarta 55281, Indonesia \\ ${ }^{2}$ Department of Chemistry, University of Gadjah Mada, Sekip Utara, Bulaksumur, Yogyakarta 55281, Indonesia \\ ${ }^{3}$ Center for Science and Technology of Advanced Materials, National Nuclear Energy Agency, Puspiptek Area Serpong, \\ Tangerang Selatan 15310, Indonesia \\ ${ }^{4}$ Synchrotron Light Research Institute (SLRI), 111 University Avenue, Muang District, Nakhon Ratchasima 30000, Thailand
}

\section{ARTICLE INFO}

Article history:

Received 12 March 2018

Received in revised form 23 February 2019

Accepted 11 March 2019

Keywords:

Mesoporous;

Nanostructure;

Small angle scattering;

$\mathrm{X}$-ray synchrotron

\begin{abstract}
A B S T R A C T
Ordered pores structure analysis of mesoporous silica materials using a template of poly(ethylene oxyde)-poly(propylene oxide)-poly(ethylene oxide), PEO-PPO-PEO, triblock copolymer or Pluronics in numerous synthesis conditions has been conducted. Two different length of hydrophilic chain of Pluronics, i.e., P123 $\left(\mathrm{EO}_{20} \mathrm{PO}_{70} \mathrm{EO}_{20}\right)$ and $\mathrm{F} 127\left(\mathrm{EO}_{106} \mathrm{PO}_{70} \mathrm{EO}_{106}\right)$, produced two different fine pore structures, which were basically hexagonal and cubic. A highly ordered pore structure, confirming with many Bragg peaks, was clearly obtained with the lattice parameters in nanometer scale from analyzing the synchrotron small angle X-ray scattering (SAXS) data. Meanwhile, the surface area and pores size of mesoporous silica determined by nitrogen absorption clearly support the analysis of SAXS data, presenting a complete information of pore order characteristics. This paper shows how the synthesis parameters, such as length of hydrophilic chains, silica precursor concentration, Al:Si ratio and synthesis methods, are related to the structure and order of the pores formed. The SAXS patterns show that the pore order increases with increasing concentration of sodium silicate and decreases with longer sonication time.
\end{abstract}

(C) 2020 Atom Indonesia. All rights reserved

\section{INTRODUCTION}

Research on ordered mesoporous materials has gained increasing interest since the discovery of those materials in 1992. Their ability to interact with atoms, ions, molecules, and nanoparticles, not only at the surface but also throughout the bulk, make these materials' properties outstanding and bear potential for promising applications in various fields [1], particulary in catalysis and separation technology $[2,3]$.

Several previous studies have reported that mesoporous materials can be synthesized using

\footnotetext{
${ }^{*}$ Corresponding author.

E-mail address: giri@batan.go.id

DOI: https://doi.org/10.17146/aij.2020.835
}

various constituents. Oxide materials are the most commonly found as mesoporous materials, i.e., $\mathrm{SiO}_{2}, \mathrm{TiO}_{2}, \mathrm{ZnO}, \mathrm{Fe}_{2} \mathrm{O}_{3}$, etc. Beside those oxide materials, several studies have also reported that carbon and metal oxide combinations can be synthesized as porous materials. Among these porous materials, mesoporous silica is undergoing rapid development. Santa Barbara Amorphous (SBA) is one of mesoporous silica families that has been developed for the last few years [4]. SBA-15 and SBA-16 have been selected to be the main object of this study because they can be synthesized by environmentally friendly triblock copolymers [5].

SBA-15 and SBA-16 have become two mesoporous silica materials studied intensely and have gained the most attention. Several previous 
studies have reported that SBA-15 is a mesoporous silica with cylindrical pores in a hexagonal order corresponding to $p 6 \mathrm{~mm}$ space group, whereas the structure of SBA-16 consists of body centered cubic arrangement of mesoporous spheres with 8 apertures to the nearest neighbors corresponding to $\operatorname{Im} \overline{3} m$ space group [6].

Generally, many previous studies have focused more on how to synthesize mesoporous materials using different synthesis methods such as conventional sol-gel processes [7], liquid crystal templating method [8], or nanocasting strategy [9]. However, to date, only a few publications have focused on the effects of treatments given when synthesizing ordered of pores. For optimal application, techical information on the optimized synthesis conditions and other related synthesis variables for pore order controlling is very important [1]. For example, to fabricate a filtration material, the material must be designed to have a permeable property. Information on how to control structure, size and pore order will be helpful in designing the permeable properties of the material. Pore can also be used as a second phase to design materials with tailored properties, and in this case it is necessary to control both porosity and pore size [10].

Information on pore structures can be obtained by certain characterizations, for example, the determination of how the mesoporous structure is developed at nanometric scale. The selection of characterization techniques used is based on the focus of information of interest. There are several characterization techniques commonly used such as electron microscopy, X-ray diffraction and small-angle scattering (SAS). For information on the structure of materials, X-ray diffraction is generally used, whereas surface morphology is commonly examined by electron microscopy, and information on the structures hierarchy of mesoporous materials is more appropriately determined by small-angle scattering technique [11] Different characterization techniques have different length scales capabilities, and therefore a combination of techniques is often needed in order to obtain a complete picture of the nucleation and growth of the mesoporous materials. A small-angle $X$-ray scattering (SAXS) is an important nondestructive tool to obtain information about structural changes in a porous medium. By using synchrotron X-ray results as a base for calculations, it is possible, for example, to reconstruct the formation of silica mesoporous, revealing details of the silica network and identifying the appearance of long-range order in the system. We therefore decided to perform a SAXS experiment.

This article reports the pore order of mesoporous silica material synthesized by using
Pluronic copolymers with varied treatment parameters, i.e., variation in stirring temperature, silica precursor concentration, $\mathrm{Al}: \mathrm{Si}$ ratio and sonication time. The results obtained from this study are expected to provide a detailed picture of the fabrication mechanism of mesoporous silica material with a certain pore order in accordance with its intended applications in the future.

\section{EXPERIMENTAL METHODS}

\section{Materials}

The silica precursors used in this study were silica obtained from rice husk ash extraction (for samples with U series code) and Tetraethylorthosilicate (TEOS) as source of $\mathrm{SiO}_{2}$ (for samples with $\mathrm{P}$ and $\mathrm{N}$ series code). In addition, Triton $\mathrm{X}-100$, Aquades, $\mathrm{NaOH} 1 \mathrm{~N}$, Etanol $97 \%$, and $\mathrm{HCl}$ $(1 \%$ and $0.1 \mathrm{~N})$, were also used in this study. All of those chemicals were purchased from Merck without further purification. As surfactant, Pluronic P123 was used for samples with sample code U, meanwhile Pluronic F127 was used for samples with code samples $\mathrm{N}$ and $\mathrm{P}$.

\section{Synthesis}

The series of SBA-15 and SBA-16 were synthesized using poly(ethylene oxyde)poly(propylene oxide)-poly(ethylene oxide) triblock copolymer in a ternary copolymer-ethanol-water system and low acid concentration. For SBA-15 samples with sample code $\mathrm{U}$, the aqueous mixture of Pluronic P123 $\left(\mathrm{EO}_{20} \mathrm{PO}_{70} \mathrm{EO}_{20}\right)$ copolymer with hydrochloric acid $(\mathrm{HCl})$ was used to achieve ordered self-assembly of sodium silicate as the silica source. In a typical synthesis, $4 \mathrm{~g}$ of copolymer P123 was dissolved in $150 \mathrm{~mL}$ hydrochloric acid $\mathrm{HCl} 1.6 \mathrm{M}$ and the addition of sodium silicate in several variations of concentration. This mixture was stirred until completely dissolved and formed a gel. Subsequently, the gel underwent a sonication process with varied sonication time. After settling at $100{ }^{\circ} \mathrm{C}$ for 1 hour, the precipitate was washed with ethanol and aquades until neutral $\mathrm{pH}$ was obtained. The drying process was carried out at $120{ }^{\circ} \mathrm{C}$ for 1 hour and calcination at $550^{\circ} \mathrm{C}$ for 6 hours to remove the P123 surfactant.

On the other hand, the SBA-16 samples (sample code of $\mathrm{N}$ and $\mathrm{P}$ ) were synthesized using Pluronic F127 $\left(\mathrm{EO}_{106} \mathrm{PO}_{70} \mathrm{EO}_{106}\right)$. In a typical synthesis, sample code $\mathrm{N}$ was synthesized by direct synthesis method (direct grafting method), in which the addition of alumina precursors to the aqueous 
mixture of Pluronic F127 copolymer (with TEOS as the silica source), hydrochloric acid and aquades was carried out directly. In contrast, the sample code $\mathrm{P}$ was prepared by indirect synthesis method (post-grafting method), where the addition of alumina was done after the calcination of the SBA-16 template. Both series of these samples $(\mathrm{N}$ and $\mathrm{P})$ were synthesized with variations in the mass ratio of alumina to silica and stirring temperature. Samples with those variations were to be further characterized by SAXS method in order to obtain the information on structural and pore order changes of the mesoporous silica in nanometer scale level. Table 1 summarizes the sample nomenclature and treatment variation given to each sample.

\section{Characterization}

The main characterization technique used in this study was small-angle X-ray scattering (SAXS). The characterization of SAXS was performed with the source of X-ray synchrotron in beamline 1.3 at Synchrotron Light Research Institute (SLRI), Thailand. As a comparison data, adsorption method was also used to observe the pore structure.

Table 1. Sample nomenclature and treatment variation

\begin{tabular}{|c|c|}
\hline SampleCode & Treatment Variation \\
\hline $\mathrm{U} 1$ & $10 \mathrm{~mL} \mathrm{NaSiO}_{2}$ and 1 hour Sonication \\
\hline $\mathrm{U} 2$ & $30 \mathrm{~mL} \mathrm{NaSiO}$ and 1 hour Sonication \\
\hline U3 & $50 \mathrm{~mL} \mathrm{NaSiO}$ and 1 hour Sonication \\
\hline $\mathrm{U} 4$ & $70 \mathrm{~mL} \mathrm{NaSiO}{ }_{2}$ and 1 hour Sonication \\
\hline U5 & $50 \mathrm{~mL} \mathrm{NaSiO}_{2}$ and 0.5 hour Sonication \\
\hline U6 & $50 \mathrm{~mL} \mathrm{NaSiO}_{2}$ and 2 hour Sonication \\
\hline $\mathrm{U} 7$ & $50 \mathrm{~mL} \mathrm{NaSiO}$ and 3 hour Sonication \\
\hline $\mathrm{N} 1$ & Stirring at $28^{\circ} \mathrm{C}(\mathrm{Al}: \mathrm{Si}=1: 20)$ \\
\hline $\mathrm{N} 2$ & Stirring at $35^{\circ} \mathrm{C}(\mathrm{Al}: \mathrm{Si}=1: 20)$ \\
\hline $\mathrm{N} 3$ & Stirring at $45^{\circ} \mathrm{C}(\mathrm{Al}: \mathrm{Si}=1: 20)$ \\
\hline N4 & Stirring at $52^{\circ} \mathrm{C}(\mathrm{Al}: \mathrm{Si}=1: 20)$ \\
\hline N5 & $\mathrm{Al}: \mathrm{Si}=1: 10\left(\mathrm{~T}_{\text {stirring }}=45^{\circ} \mathrm{C}\right)$ \\
\hline N6 & $\mathrm{Al}: \mathrm{Si}=1: 30\left(\mathrm{~T}_{\text {stirring }}=45^{\circ} \mathrm{C}\right)$ \\
\hline N7 & $\mathrm{Al}: \mathrm{Si}=1: 40\left(\mathrm{~T}_{\text {stirring }}=45^{\circ} \mathrm{C}\right)$ \\
\hline $\mathrm{P} 1$ & $\mathrm{Al}: \mathrm{Si}=1: 10\left(\mathrm{~T}_{\text {stirring }}=45^{\circ} \mathrm{C}\right)$ \\
\hline $\mathrm{P} 2$ & $\mathrm{Al}: \mathrm{Si}=1: 20\left(\mathrm{~T}_{\text {stirring }}=45^{\circ} \mathrm{C}\right)$ \\
\hline P3 & $\mathrm{Al}: \mathrm{Si}=1: 30\left(\mathrm{~T}_{\text {stirring }}=45^{\circ} \mathrm{C}\right)$ \\
\hline P4 & $\mathrm{Al}: \mathrm{Si}=1: 40\left(\mathrm{~T}_{\text {stirring }}=45^{\circ} \mathrm{C}\right)$ \\
\hline P5 & Stirring at $35^{\circ} \mathrm{C}(\mathrm{Al}: \mathrm{Si}=1: 20)$ \\
\hline P6 & Stirring at $40^{\circ} \mathrm{C}(\mathrm{Al}: \mathrm{Si}=1: 20)$ \\
\hline P7 & Stirring at $45^{\circ} \mathrm{C}(\mathrm{Al}: \mathrm{Si}=1: 20)$ \\
\hline P8 & Stirring at $50^{\circ} \mathrm{C}(\mathrm{Al}: \mathrm{Si}=1: 20)$ \\
\hline
\end{tabular}

The selection of these synthesis variables was based on a research report by Johanson, et al. [12], which states that addition of salt, co-surfactant or changing the hydrothermal treatment are ways to change the pore properties.

\section{Analysis}

The first procedure performed after obtaining experimental scattering data using SAXS was data reduction procedure. The raw data were stored in *.mccd file and *.txt file for each sample and background. The data reduction procedure was performed using SAXSIT software [13] in order to substract background parameters and calculate scattering profile of the intensity versus momentum transfer $q$.

The final conversion of SAXS data were stored as *.xy file and converted into *.rd file by using Conv-X XRD file conversion program. The converted data were subsequently analyzed by a single line method and Rietveld refinement using X'Pert High Score Plus Program. X'Pert High Score determined peak positions by searching for negative regions in the second derivative of the scan. This method allows accurate detection of small peaks (shoulders) overlapped by large peaks, which is not possible by evaluating zero-crossings of the first derivative. The second derivative was calculated with a sliding polynomial filter after Savitsky \& Golay. The exact peak position was then determined by fitting a parabola to the top of the smoothed data or the second derivative.

X'Pert High Score uses the Pseudo-Voigt profile function, which is the weighted mean between a Lorentz and a Gauss function:

$$
G_{i k}=\gamma \frac{C_{0}^{1 / 2}}{H_{k} \pi}\left[1+C_{0} X_{i k}^{2}\right]^{-1}+C
$$

with :

$$
C=(1-\gamma) \frac{C_{1}{ }^{1 / 2}}{H_{k} \pi^{1 / 2}} \exp \left[-C_{1} X_{i k}{ }^{2}\right]
$$

where $H_{\mathrm{k}}$ is the full-width at half maximum (FWHM) of the $k$-th Bragg Reflection, $X_{\text {ik }}=\left(2 \theta_{\mathrm{i}}-2 \theta_{\mathrm{k}}\right) / H_{\mathrm{k}}$.

\section{RESULTS AND DISCUSSION}

\section{Pore structure (SAXS)}

Figure 1 shows the synchrotron SAXS patterns for the U sample code. Based on this SAXS pattern, the mesoporous silica, which was synthesized using Pluronic P123 as surfactant, shows scattering peaks in the range of about $0.4<q$ $<3 \mathrm{~nm}^{-1}$. The reflection of SAXS patterns indicates that the (100) peak is the dominant plane present in all $U$ samples as well as the occurrence of peaks (200) and (210) in samples coded U4 and U5 (Fig. 1(a)). Indexing of these peaks has resulted 
in two dimensional hexagonal $(p 6 \mathrm{~mm})$ mesoporous structure, thus providing an indication of $16 \mathrm{~mm}$ pore structure for SBA-15, as has been reported by some previous studies $[5,6,14]$. The results also share similarities with the results reported by ZienkiewiczStrzałka et al. [15], which indicate that the SAXS pattern for SBA-15 has scattering peak characteristics at (100) and (200). The appearance of peak (210) indicates good textural uniformity in this material [16].

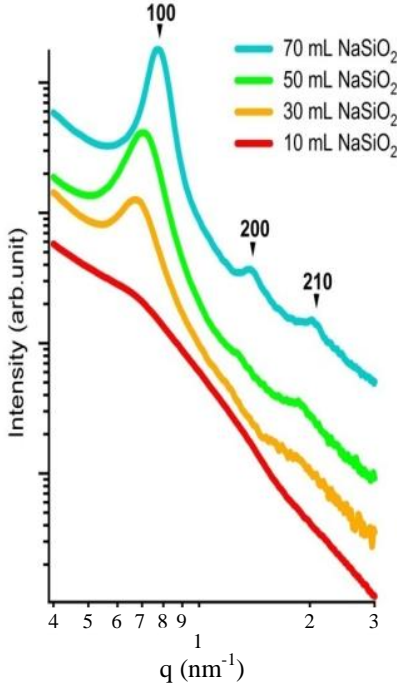

(a)

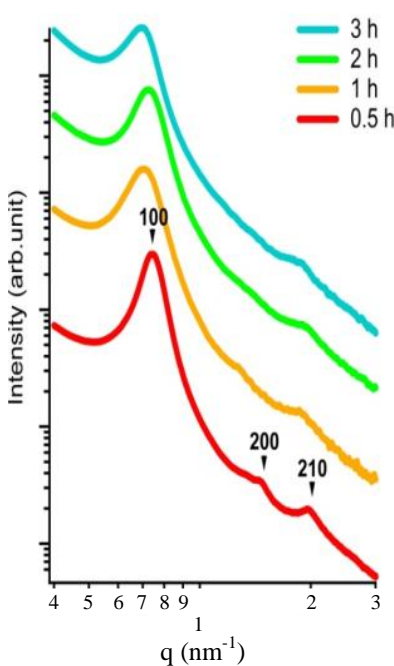

(b)
Fig. 1. SAXS scattering curves for sample series $\mathrm{U}$ (a) $\mathrm{NaSiO}_{2}$ variation (b) Sonication time variation.

Figure 1(a) shows that as the sodium silicate concentration increases, the scattering pattern tends to indicate higher pore order, which is marked by the increasing number of peaks. It can also be seen that at lower sodium silicate concentration, only a broad correlation peak is observed, suggesting a lack of long-range order in the fabricated SBA-15 mesoporous silica material [17]. Otherwise, when the concentration of sodium silicate was made constant, samples with longer sonication time (Fig. 1(b)) produce SAXS patterns with a reduced pore order, which is marked by a decrease in the number of peaks. The SAXS patterns in Fig. 2 show a dominant intense peak appearing in all $\mathrm{N}$ series samples, observed for samples with both stirring temperature variation (Fig. 2(a)) and $\mathrm{Al}: \mathrm{Si}$ ratio variation (Fig. 2(b)). This peak is futher identified as (110) plane. In addition, also identified are three weak peaks as (200), (211) and (310) planes. These peaks indicate SBA-16 characteristics that have a 3-D cubic pore structure corresponding to $\operatorname{Im} 3 m$ space group, as has been reported by some previous studies [3-5].

If compared with the SAXS patterns in Fig. 1, the results in Fig. 2 affirm that different Pluronic surfactants produce different pore structures.
Pluronic is a non-ionic triblock copolymers Consisting of hydrophilic polyethylene-oxide chains (PEO) and hydrophobic polypropylene-oxide chains (PPO).

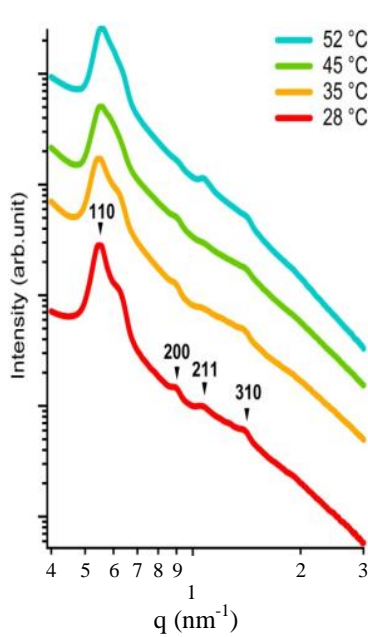

(a)

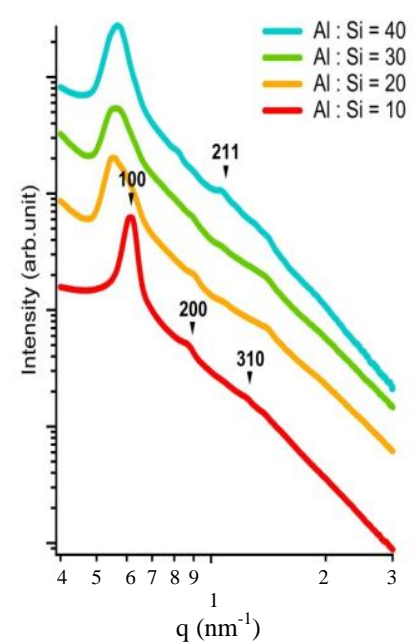

(b)
Fig. 2. SAXS scattering curves for sample series $\mathrm{N}$ (a) Stirring temperature variation (b) $\mathrm{Al}: \mathrm{Si}$ ratio variation.

The use of different notations for Pluronic P123 and Pluronic F127 refers to different molecular weight and PEO/PPO ratio. Pluronic P123 is a paste composing about $3600 \mathrm{~g} / \mathrm{mol} \mathrm{PPO}$ and $30 \mathrm{wt} \%$ PEO while F127 is solid flakes with the same weight of PPO but 70 wt $\%$ PEO.

This difference in wt\% PEO give rise to the variation of pore structure observed in the mesoporous silica. Pluronic P123 (Fig. 3(a)) with $30 \%$ PEO tends to form hexagonal pore structure, whereas Pluronic F127 (Fig. 3(b)) with 70 wt\% PEO tends to more easily form pores with cubic structures. This explanation is illustrated in Fig. 3.

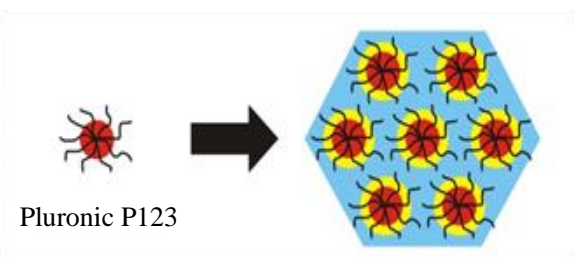

(a)

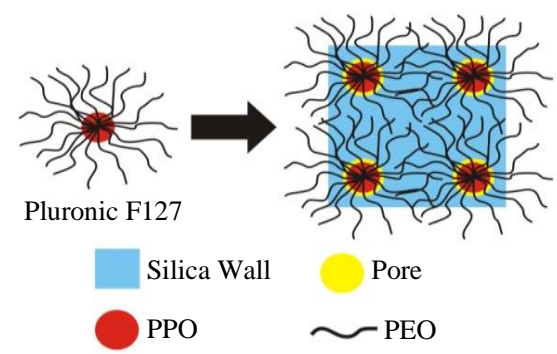

(b)

Fig. 3. Pore structure formation mechanism using two Pluronic types, (a) Pluronic P123 and (b) Pluronic F127. 
SAXS patterns of samples $\mathrm{P}$ are shown in Fig. 4. Although the $\mathrm{N}$ and $\mathrm{P}$ samples were synthesized using the same base material and the same treatment variation, however, different synthesis methods have resulted in slightly different scattering patterns. Both samples series tend to have one dominant peak identified as (110) followed by two or three other low peaks identified as (200), (211) and (310), but the peak positions between samples $\mathrm{N}$ and $\mathrm{P}$ have different scattering momentum values.

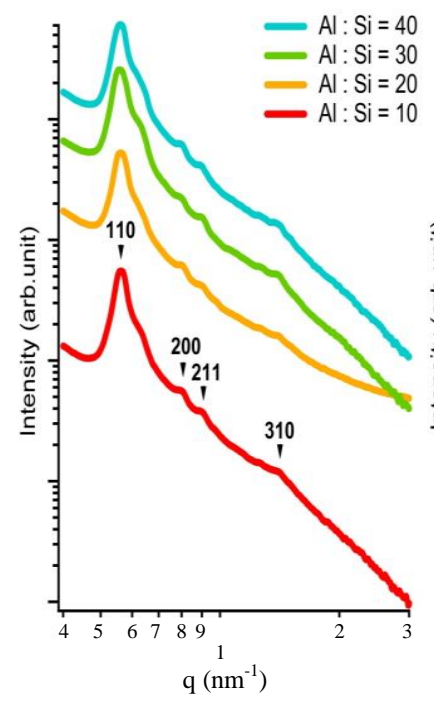

(a)

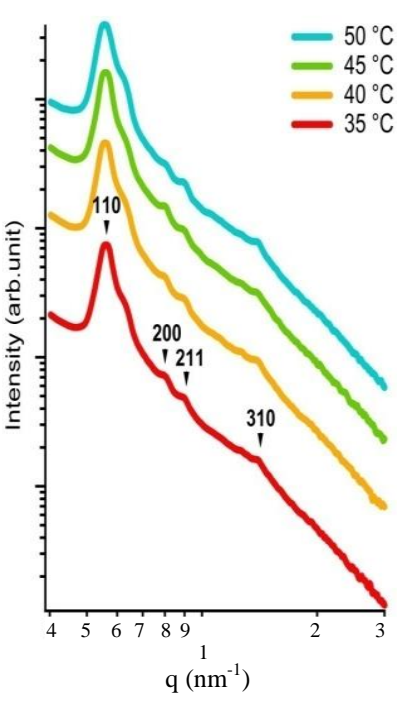

(b)
Fig. 4. SAXS scattering curves for sample series $\mathrm{P}$ (a) Al:Si ratio variation (b) Stirring temperature variation.

\section{Surface area and pore size}

The pore characteristics (for P-series) examined by nitrogen adsorption method are given in Table 2. It appears that variation in $\mathrm{Al}: \mathrm{Si}$ ratio does not spesifically affect the surface area and pore volume formed. We believed that the use of post grafting method as a synthesis method has contributed to this result. In this method, the addition of $\mathrm{Al}$ was carried out after the SBA-16 calcination process, in which the surface area and pore volume formed are not significantly affected.

Table 2. Adsorption of nitrogen characterization results for P-series.

\begin{tabular}{cccc}
\hline $\begin{array}{c}\text { Sample } \\
\text { Code }\end{array}$ & $\begin{array}{c}\text { Al:Si } \\
\text { Ratio }\end{array}$ & $\begin{array}{c}\text { Surface Area } \\
\left(\mathrm{m}^{2} / \mathrm{g}\right)\end{array}$ & $\begin{array}{c}\text { Pore Diameter } \\
\text { (nanometer) }\end{array}$ \\
\hline \multirow{4}{*}{$\mathrm{P}$} & 10 & 764.1 & 3.41 \\
& 20 & 762.8 & 3.43 \\
& 30 & 792.1 & 3.36 \\
& 40 & 781.9 & 3.41 \\
$\mathrm{~N}$ & 10 & 1153.6 & 3.26 \\
& 20 & 1407.4 & 3.28 \\
& 30 & 1412.2 & 3.34 \\
\hline
\end{tabular}

Contrary to the $\mathrm{P}$ samples, the increase of $\mathrm{Al}: \mathrm{Si}$ ratio in the direct synthesis method (Sample $\mathrm{N}$-series) leads to an increase in pore diameter. Table 3 shows an Al/SBA-16 buffer sample with code N3 with its values of specific surface area and pore volume. Largest specific area indicates an increasing number of heteroatoms bound to silanol groups in the SBA-16. However, in the sample code N7, the spesific surface area decreases. This decrease indicates that the absorption of heteroatom aluminium has resulted in more empty space in the mesoporous silica SBA-16 to be filled by alumina, causing a decrease in pore volume and specific surface area.

Table 3. Adsorption of nitrogen characterization results for sample code U.

\begin{tabular}{ccc}
\hline $\begin{array}{c}\mathrm{NaSiO}_{2} \\
\text { Ratio }\end{array}$ & $\begin{array}{c}\text { Surface Area } \\
\left(\mathrm{m}^{2} / \mathrm{g}\right)\end{array}$ & $\begin{array}{c}\text { Pore Diameter } \\
\text { (nanometer) }\end{array}$ \\
\hline 30 & 65.5 & 5.44 \\
50 & 146.6 & 4.69 \\
70 & 125.9 & 4.59 \\
\hline
\end{tabular}

The result of nitrogen adsorption shows that the increase of $\mathrm{Al}: \mathrm{Si}$ ratio on samples series $\mathrm{P}$ and $\mathrm{N}$ significantly increases pore diameter, pore volume, and surface area. However, $\mathrm{Al}: \mathrm{Si}$ ratio variation has no significant effect on the pore structure, which is indicated by the peak position and the $h k l$ value, as shown in the previous SAXS results. The ability of hydrophilic EO chains to interact with cationic oligomeric silica through electrostatic interactions and hydrogen bonding are the reasons behind this insignificancy.

In contrast to the results shown in the previous table, Table 3 shows different pore characteristics for U-series. Although the surfactant used has the same PPO weight, the use of different silica precursors has an effect on pore size of the U-series. When sodium silicate is used as the precursor of silica, the properties of the pluronics are strongly influenced by the presence of $\mathrm{Na}^{+}$. For example, the presence of $\mathrm{Na}^{+}$cations reduces the critical micelle temperature (CMT) but increases the cloud point (CP) and solubility of Pluronic P123. In addition, sodium ions increase the solvophobicity of PEO and PPO chains [11]. Using quantum chemistry approach, there are two main effects of the presence of $\mathrm{Na}^{+}$on solvophobic forces, i.e., firstly, the direct effect on electrostatic terms (the free energy of interaction $\Delta G_{\text {int }}$ and the free energy of reduction $\left.\Delta G_{i n t}\right)$ and secondly, a change in the cavity surface squeeze effect [18]. As a result, the $\mathrm{Na}^{+}$absorbed on the silica surface will coordinate with oxygen atoms (from the silanol groups between two particles) and suface bonded water. Thus linkage between particles can be reached and ionic strength increases [19]. This leads to an increase in the core radius and a 
slight increase in the pore size (as shown in the schematic model presented in Fig. 3(b)).

\section{Pore order studies}

The SAXS scattering patterns expressed in momentum scattering can be identified as the diffraction characteristics expressed in $2 \theta$ positions as follows:

$$
2 \theta=2 \arcsin \frac{q \lambda}{4 \pi}
$$

For SBA-15, 2-D hexagonal structure, the unit cell parametes were calculated using the formula:

$$
a=\frac{2 d_{100}}{\sqrt{3}}
$$

where $d_{100}$ represents the $d$-spacings value of the (100) diffraction peak in diffraction patterns of samples. The pore wall thickness was calculated from the formula $t=a-D$, where $a$ represents the unit cell and $D$ represents the pore diameter calculated using nitrogen absorption method.

On the other hand, the unit cell parameters for SBA-16, which is cubic structure, was calculated using the formula $a=d_{110} \sqrt{2}$. The pore wall thickness of SBA-16 was calculated from the following formula:

$$
t=\frac{\sqrt{3}}{2} a_{0}-D
$$

A noticeable decrease in $d$-spacing occurs with increasing $\mathrm{SiO}_{2}$ : P123 ratio (sample code U). When associated with crystallography, it can be seen that the decrease in the $d$-spacings value (inversely proposional to $2 \theta$ ) is related to the greater value of lattice parameters. In addition, the relative intensity ratio between the first low angle reflection (100) and the reflections at higher $2 \theta$ increases with increasing $\mathrm{SiO}_{2}$ : $\mathrm{P} 123$ ratio, and high degree of order is retained, suggesting differences in the pore wall thickness to pore size ratio and, most likely, an increase of the wall thickness.

Choi et.al [20] previously has reported that the low reaction rate, due to low acidity in the synthesis, gives the silica species time to condense on the PEO chains. Higher amounts of silicate species allowed to combine with hydrated PEO chains of $\mathrm{P} 123$ at high $\mathrm{SiO}_{2}: \mathrm{P} 123$ ratios will lead to a significant decrease in the pore connecting PEOPEO interaction between adjacent micelles and to pore-wall thickening. Thus, the $\mathrm{SiO}_{2}: \mathrm{P} 123$ ratio seems to be the main factor affecting the degree of pore connectivity under the present low $\mathrm{HCl}$ concentration.
Table 4. Existing $h k l$ peaks and lattice parameter for all samples.

\begin{tabular}{ccc}
\hline Sample & Existing Peaks & $\begin{array}{c}\text { Lattice Parameter } \\
\text { (nanometer) }\end{array}$ \\
\hline U1 & - & - \\
U2 & $(100)$ & 12.1 \\
U3 & $(100)$ & 11.6 \\
U4 & $(100)(200)(210)$ & 10.5 \\
U5 & $(100)(200)(210)$ & 10.9 \\
U6 & $(100)$ & 11.2 \\
U7 & $(100)$ & 11.7 \\
N1 & $(110)(200)(211)(310)$ & 18.1 \\
N2 & $(110)(200)(211)(310)$ & 18.1 \\
N3 & $(110)(200)(211)(310)$ & 17.9 \\
N4 & $(110)(211)(310)$ & 17.8 \\
N5 & $(110)(200)(310)$ & 16.2 \\
N6 & $(110)(211)$ & 17.7 \\
N7 & $(110)(200)(211)$ & 17.5 \\
P1 & $(110)(200)(211)(310)$ & 17.6 \\
P2 & $(110)(200)(211)$ & 17.7 \\
P3 & $(110)(200)(211)(310)$ & 17.8 \\
P4 & $(110)(200)(211)(310)$ & 17.7 \\
P5 & $(110)(200)(211)(310)$ & 17.7 \\
P6 & $(110)(200)(211)(220)$ & 17.8 \\
P7 & $(110)(200)(211)$ & 17.7 \\
P8 & $(110)(200)(211)$ & 16.2 \\
\hline
\end{tabular}

Table 4 summarizes the existing peaks and the calculated lattice parameters for all samples. The broadening and disappearance of certain peaks indicate a structural transformation of silica template.

For example, in certain parts there may occur a pore structure transformation from an open-pore structure system into a closed pore system or vice versa, resulting in broadening or disappearing of the peak in a particular direction. It is clear that in the samples U, the pores begin to form a high order after addition of $70 \mathrm{~mL}$ sodium silicate. This clearly proves that the EO chains in Pluronic PEO-PPOPEO interact with oligomeric cationic silica, either in the form of electrostatic bonds or with hydrogen bonds. As the silica base supply increases, the EO chain withdrawal from the surfactant nucleus becomes longer. This EO chain withdrawal effect causes the formation of pores with higher order. On the other hand, the absence of the peak in the sample code U1 indicates that the pore's order is extinct [16].

The information of pore size from nitrogen adsorption characterization and pore distance from SAXS pattern analysis can be used to determine the thickness of the pore frame. The proposed model is presented in Fig. 5. 


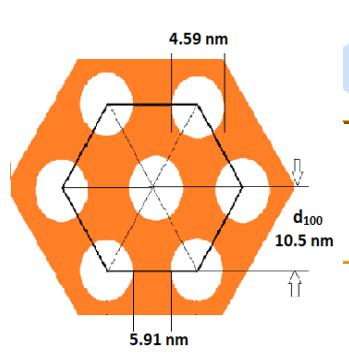

(a)

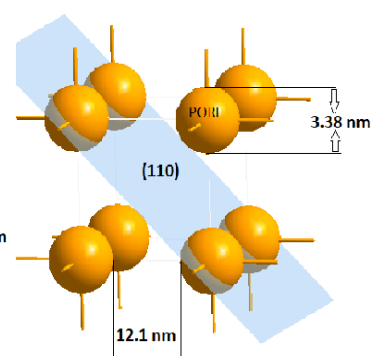

(b)
Fig. 5. Model of pore that formed on mesoporous silica material for (a) 2-D hexagonal structure and (b) cubic structure.

\section{CONCLUSION}

The analysis of SAXS data supported by nitrogen adsorption method has precisely given a complete information on pore order characteristics. It can be concluded from this study that two different length of hydrophilic chain of Pluronics used as surfactant basically produces two different fine pore structures. Pluronic P123 (sample U-series) tends to form 2-D hexagonal structure while Pluronic F127 (sample P and N series) tends to more easily form pores with cubic structure.

The treatment given during the synthesis process affects the pore order characteristics. As the sodium silicate concentration increases in the SBA-15 synthesis process, the scattering pattern indicates a higher pore order, which is marked by the increasing number of peaks. Otherwise, when the concentration of sodium silicate is made constant, sample U-series with longer sonication time produce SAXS patterns indicating decrease in pore order.

The use of different synthesis methods (i.e., direct synthesis method for $\mathrm{N}$-series and postgrafting synthesis method for P-series) has resulted in slightly different scattering momentum values, but both sample series tend to have one dominant peak identified as (110) followed by two or three other low peaks identified as (200), (211) and (310).

\section{ACKNOWLEDGMENT}

The authors would like to express their gratitude to Ms. Sri Sundari Retnoasih and Ms. Atanasia Elra Andjioe for sample preparation and data collection of SAXS experiment. This research is partialy funded by a grant from the Ministry of Research, Technology, and Higher Education of Indonesia through Insinas Research Grant 2014 (RT-2013-1630 and RT-2014-1357).

\section{REFERENCES}

1. W. Li and D. Zhao, Chem. Commun. 49 (2013) 943.
2. M.J. Hollamby, D. Borisova, P. Brown et al., Langmuir 28 (2012) 4425.

3. A. Eftekhari, Microporous Mesoporous Mater. 243 (2017) 355.

4. G.F. Andrade, D.C.F. Soares, R.G. dos Santos et al., Microporous Mesoporous Mater. 168 (2013) 102.

5. V. Meynen, P. Cool and E.F. Vansant, Microporous Mesoporous Mater. 125 (2009) 170.

6. G. Gonzalez, A. Sagarzazu, A. Cordova et al., Microporous Mesoporous Mater. 256 (2018) 251.

7. N.I. Vazquez, Z. Gonzalez, B. Ferrari et al., Bol. Soc. Esp. Cerámica Vidr. 56 (2017) 139.

8. H. Sanaeishoar, M. Sabbaghan and F. Mohave, Microporous Mesoporous Mater. 217 (2015) 219.

9. V.K. Tomer and S. Duhan, Sens. Actuators B Chem. 223 (2016) 750.

10. S. Mazumder, D. Sen and A.K. Patra, Pramana Journal of Physics 63 (2004) 165.

11. S. Hadi, Suryajaya, I. Wijaya et al., Atom Indonesia 44 (2018) 9.

12. E.M. Johansson, Controlling the Pore Size and Morphology of Mesoporous Silica, Ph.D. Thesis, Linköping University (2010).

13. R. Phinjaroenphan, S. Soontaranon, P. Chirawatkul et al., J. Phys. Conf. Ser. 425 (2013) 132019.

14. J.P. Thielemann, F. Girgsdies, R. Schlögl et al., J. Nanotechnol. 2 (2011) 110.

15. M. Zienkiewicz-Strzałka, M. Skibińska and S. Pikus, Nucl. Instrum. Methods Phys. Res. Sect. B Beam Interact. Mater. At. 411 (2017) 72 .

16. Y.-J. Han, J.M. Kim and G.D. Stucky, Chem. Mater. 12 (2000) 2068.

17. R.M. Dorin, D.S. Marques, H. Sai et al., ACS Macro Lett. 1 (2012) 614.

18. O. Sinanoğlu, Int. J. Quantum Chem. 18 (1980) 381.

19. M.-C. Pan, Y.-X. Yang, H.-P. Ying et al., J. Chem. 25 (2007) 1514.

20. M. Choi, W. Heo, F. Kleitz et al., Chem. Commun. (2003) 1340. 